\title{
Listeria Meningitis with Aspergillosis After Alemtuzumab Treatment
}

\author{
Alemtuzumab Tedavisi Sonrasında Listeria Menenjitiyle Birlikte Aspergilloz
}

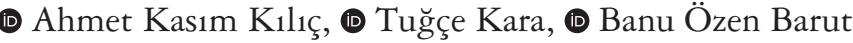 \\ University of Health Sciences Turkey, Istanbul Kartal Dr. Lutfi Kirdar Training and Research Hospital, Clinic of Neurology, Istanbul, Turkey
}

Keywords: Alemtuzumab, listeria monocytogenesis, aspergillosis, multiple sclerosis

Anahtar Kelimeler: Alemtuzumab, listeria monositogenez, aspergilloz, multipl skleroz

\section{Dear editor,}

A 40 year-old male patient had been diagnosed as having multiple sclerosis (MS) in 2000 with two relapses in two years of onset and treated with interferon beta- $1 \mathrm{~b}$ subcutaneously initially. He had his third attack seven years later and fourth attack in sixteenth year. One year later from last relapse, natalizumab was started. After three natalizumab infusions, the patient discontinued natalizumab due to side effects. Two months after natalizumab cessation, he had a relapse and cyclophosphamide (CYC) was planned. After two CYC infusions, the patient preferred not to continue due to side effects again. Alemtuzumab treatment was planned and started in August 2018. After second infusion, headache and fever were seen. Complete blood count (CBC) and biochemistry showed leukocytosis and lymphopenia [white blood cells (WBC): $23.200 / \mathrm{mm}^{3}$, lymphocyte: 0] and high levels of procalcitonin $(10.940 \mathrm{ng} / \mathrm{ml})$. Blood and urine cultures resulted as negative. Patient responded to meropenem antibiotherapy, and leukocytosis and fever improved. In August 2019, second year alemtuzumab dose was given to patient with acyclovir prophylaxis and listeria free-diet was suggested before treatment onset. After treatment completion, patient had itching and rashlike findings, and an antihistaminic agent was recommended. Two days after treatment end, patient was admitted with headache, and vomitting to emergency room. Leukocytosis [WBC: 18.500/ $\mathrm{mm}^{3}$ (neutrophil: $15.600 / \mathrm{mm}^{3}$, lymphocyte: $700 / \mathrm{mm}^{3}$ )] and high C-reactive protein (CRP: 17) were observed. He had fever (38.5 $\left.{ }^{\circ} \mathrm{C}\right)$. Meropenem was empirically started, acyclovir dosage was increased to $2 \times 750 \mathrm{mg} / \mathrm{dl} \mathrm{IV}$. Control magnetic resonance imaging (MRI) of the brain and the spinal cord did not show any meningeal or paranchymal enhancement compatible with infection except chronic demyelinating MS lesions (Figure 1). At the follow-up, patient became mildly somnolant and neck stiffness developed. Lumbar puncture showed high cerebro-spinal fluid (CSF) protein (226 mg/dl), hypoglycorrhachia (CSF glucose: $38 \mathrm{mg} / \mathrm{dl}$ ). Cytologic examination of CSF revealed 500 polimorphonuclear leukocytes per ml. CSF viral/fungal panel, CSF-ARB and tuberculosis-polymerase chain reaction resulted negative. CSF culture resulted positive for L. monocytogenesis. Follow-up CBCé and serological tests showed leukocytosis, and increase in CRP and procalcitonin levels (WBC: 22.000/ $\mathrm{mm}^{3}$, CRP: 339, procalcitonin: 6.680). Antibiotherapy was changed to ampicilline-gentamicin IV. Despite the decline of leukocytosis and CRP level after antibiotherapy change, recurrence of fever was noticed. Blood galactomannan antigen was positive supporting aspergillosis. It has been known that beta-lactam antibiotic agents cause false positivity of galactomannan antigen test (1). Repeat galactomannan antigen also became positive again. Patient was accepted as having aspergillosis. Ambisome treatment was added. Despite the diagnosis of aspergillosis could not be clearly confirmed, rapid decline of fever and normalization of CRP and leukocytosis was seen after antifungal treatment.

Alemtuzumab is an efficient treatment option for patients with MS not responding to first line agents (2). It has been recommended to follow up patients for side effects up to 48 months after treatment completion (2). There has been recommendations for listeria-free diet to protect from listeria monocytogenesis infection as starting 90 days before the treatment and continuing after 30 days of treatment or antibiotherapy prophylaxis (3). Fulminant central nervous system nocardiosis in a patient with MS was reported who had abscess-like formations on her MRI (4). Postmortem pulmonary aspergillosis was reported in a patient with MS (5). The MRI of our patient did not reveal any signs of meningitis, absess or encephalitis. Due to close follow-up,

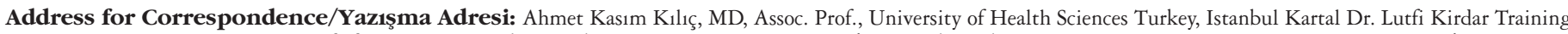
and Research Hospital, Clinic of of Neurology, Istanbul, Turkey Phone: +90 3123051806 E-mail: kasimkilic@ gmail.com ORCID: orcid.org/0000-0001-8162-391X Received/Geliş Tarihi: 03.11 .2020 Accepted/Kabul Tarihi: 10.12 .2021

${ }^{\circ}$ Copyright 2022 by Turkish Neurological Society

Turkish Journal of Neurology published by Galenos Publishing House. 

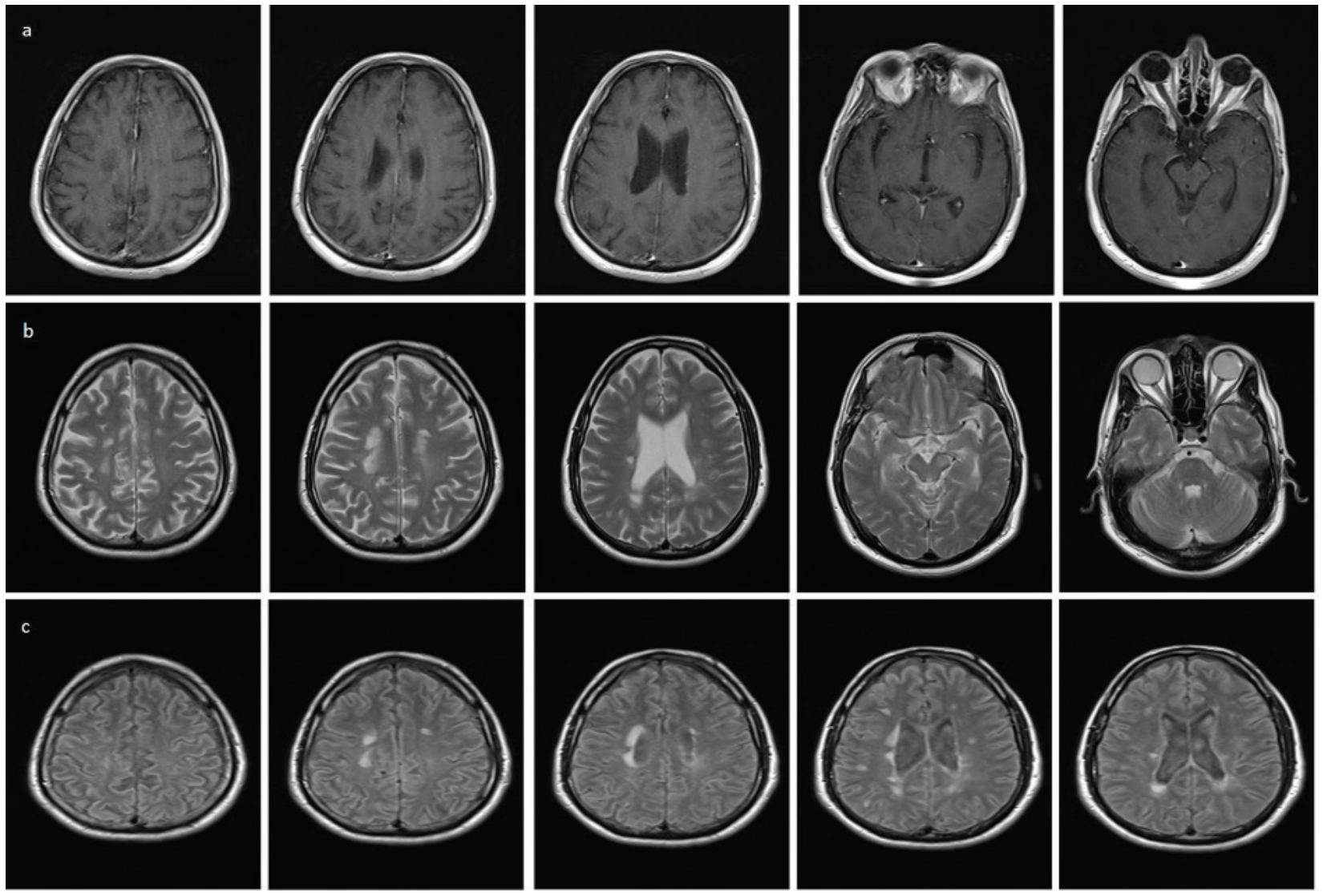

Figure 1. T1 Gd-enhanced images (a) did not show enhancement in meninges or parenchyma. T2 (b) and FLAIR (c) sequences revealed chronic demyelinating lesions on periventriculer and infratentorial regions

Gd: Gadolinium, FLAIR: Fluid-attenuated inversion recovery

patient was diagnosed rapidly. In similar situtations, all possible infectious etiologies should be investigated. To our knowledge, this is the first case of listeria menengitis and systemic aspergillosis concomittantly in an alemtuzumab-treated MS patient.

\section{Ethics}

Informed Consent: The patient's consent was obtained for this study.

Peer-review: Externally peer-reviewed.

\section{Authorship Contributions}

Surgical and Medical Practices: A.K.K., B.Ö.B., T.K., Concept: A.K.K., B.Ö.B., T.K., Design: A.K.K., B.Ö.B., T.K., Data Collection or Processing: A.K.K., B.Ö.B., T.K., Analysis or Interpretation: A.K.K., B.Ö.B., T.K., Literature Search: A.K.K., B.Ö.B., T.K., Writing: A.K.K., B.Ö.B., T.K.

Conflict of Interest: No conflict of interest was declared by the authors.
Financial Disclosure: The authors declared that this study received no financial support.

\section{References}

1. Bart-Delabesse E, Basile M, Al Jijakli A, et al. Detection of aspergillus galactomannan antigenemia to determine biological and clinical implications of beta-lactam treatments. J Clin Microbiol 2005;43:52145220.

2. Barclay K, Carruthers R, Traboulsee A, et al. Best practices for long-term monitoring and follow-up of alemtuzumab-treated MS patients in realworld clinical settings. Front Neurol 2019;10:253.

3. Buonomo AR, Zappulo E, Viceconte G, et al. Risk of opportunistic infections in patients treated with alemtuzumab for multiple sclerosis. Expert Opin on Drug Saf 2018;17:709-717

4. Penkert H, Delbridge C, Wantia N, Wiestler B, Korn T. Fulminant central nervous system nocardiosis in a patient treated with alemtuzumab for relapsing-remitting multiple sclerosis. JAMA Neurol 2016;73:757-759.

5. Russo CV, Saccà F, Paternoster M, et al. Post-mortem diagnosis of invasive pulmonary aspergillosis after alemtuzumab treatment for multiple sclerosis. Mult Scler 2020;26:123-126. 